\title{
COMPARISON OF THE RELIABILITY OF PROGRAMMABLE LOGIC CONTROLLER AND ELECTROMAGNETIC RELAY CONTROL IN INDUSTRIAL PRODUCTION LINE
}

\author{
F. Onaifo ${ }^{1,}{ }^{,}$, A. A. Okandeji' ${ }^{2}$, O. Folorunsho ${ }^{3}$, U. E. Essien ${ }^{4}$, A. O. Oyedeji ${ }^{5}$ \\ and O. R. Abolade ${ }^{6}$ \\ $\mathbf{1 , 2 , 3 , 4 , 5 , 6}$, DEPARTMENT OF ELECTRICAL/ELECTRONIC ENGINEERING, OLABISI ONABANJO UNIVERSITY, OGUN \\ STATE, NIGERIA. \\ Email addresses. ${ }^{1}$ frank.onaifo@oouagoiwoye.edu.ng, \\ 2 okandeji.alexander@oouagoiwoye.edu.ng,3 olaolu.folorunsho@oouagoiwoye.edu.ng, \\ 4 utessien91@yahoo.com, 5 oyedeji.ajibola@oouagoiwoye.edu.ng, \\ 6 abolade.raphael@oouagoiwoye.edu.ng
}

\begin{abstract}
This paper is aimed at determining the reliability of Industrial Production Line using Programmable Logic Controller. Production lines in the manufacturing sector are automated using Programmable Logic Controller module, which is programmed using programming software. The programming software used is the Siemens S7-200 while the programming language is the Ladder Programming language. Most manufacturing industries in Nigeria today still use relays for control purposes. The wirings from the control panel are so massive that any fault from the machine usually takes hours to trace and replace using the traditional electromagnetic relay. Alternative and better control methods use Programmable Logic Controller. Research articles on the reliability of PLC in a food production line are scarce. This paper is written to address this gap. The study uses the statistical analytical method, which provides useful and higher accuracy of the result as it allows high tolerance to uncertainties. The study determines the failure rate, the mean time between failures (MTBF), mean time to failure (MTTF), and availability as a means of determining the reliability of the network. Accordingly, the study showed that the mean availability of the Production line using PLC for three consecutive years is $84 \%$ while the reliability is $86 \%$. Consequently, the use of PLC should be encouraged in industrial automation as the fault can be detected easily, thereby reducing downtime as compared to the use of electromagnetic relay in the control circuitry.
\end{abstract}

Keywords: Programmable logic controller, availability, reliability, ladder programming language, relay logic.

\section{INTRODUCTION}

Control Engineering has undergone several changes over time. For centuries, humans were the only means of controlling things [1]. Programmable Logic Controller (PLC) is a modern method of automating industrial processes. PLCs are advantageous over the normal computer as they were built for rugged industrial environment. PLCs consist of input modules or points, a central processing unit (CPU), and output modules or points. An input accepts a variety of digital or analogue signals from various field devices (sensors) and converts them into a logic signal that can be used by the CPU. This paper determines the reliability of food industrial processes using programmable logic controllers.

The literature on-field failure data of production lines are scarce. Among several researchers include the work of Alexey [2] who uses skip-lot sampling to ensure fewer or zero defective products are obtained in a given manufacturing enterprise. His work focuses on the method of selection from a group of produced items. Liberopoulos and Tsarouhas [3] presented a

* Corresponding author, tel: $+234-806-476-7238$ 
case study of speeding up a croissant production line by inserting an in-process buffer in the middle of the line to absorb some of the downtime, based on the simplifying assumption that the failure and repair times of the workstations of the lines have exponential distributions. The parameters of these distributions were computed based on ten months of actual production data. In another work, Inman [4] presented four weeks of actual production data from two automotive body-welding lines. He aimed to reveal the nature of randomness in realistic problems and to assess the validity of exponential and independence assumptions for service times, interarrival times, cycles between failures, and times to repair. Georg [5] presented in his methods of different steps in the deployment of programmable logic controllers. All the processes have one common problem: its limits are exceeded. The use of software in PLC programming can only eliminate this. According to Omer et al [6], the use of PLC increases the efficiency of a production line. Sadegh and Amir [7] enumerated the advantages of PLC over the traditional relay logic. Its economic advantage is its massive production of goods thereby lowering price. Mathematically, gamma distribution and Weibull distribution competes with each other in determining the reliability of a system. Weibull distribution can also be used to determine the failure rate.

According to Gurevich [8], data released by the relay protection unit of UES of Russia in a study carried out between the year 2000 to 2009 , digital relay usage poses $89.6 \%$ correct operations with $10.4 \%$ incorrect operations, electromagnetic relay $93.53 \%$ correct operations with $6.47 \%$ incorrect operations and microelectronic relay $92.91 \%$ correct operations and $7.07 \%$ incorrect operations. Electromechanical relays become problematic when there is a fault. Tracing the fault usually takes a longer time compared to digital relays, microprocessor-based relays or electronic relays used in a programmable logic controller. Therefore, the meantime to repair is usually larger for an electromechanical-based relay in a control panel of an industrial outfit.

According to $\mathrm{H}$. Tavares et al [9], the key reliability parameters of an electronic relay is mean time between failures and mean time to repair. It is estimated that the failure rate of relay protected voltage equipment for underground cable is 0.00613 failures per year and 0.00333 failures per year for electronic digital relay operation. In this paper, the average failure rate per year for the programmable logic controller is 0.006959 .

According to Edmund O.S et al [10], electromechanical relays due to ageing, high cost of maintenance and operational errors led to the use of microprocessor-based relays. Over 30\% failure rate of electromechanical relays was as a result of malfunctioning. Other problems associated with an electromechanical relay were large spaced of an up to a room size occupied by them and few numbers of skilled personnel having the required technical knowhow in electromechanical relay maintenance. These have led to the replacement with microprocessorbased relays. Microprocessor-based relay has more availability, cheaper to maintain and can test and monitor by itself.

In this paper, a detailed statistical analysis on a set of field failure data, covering three years, was obtained from a real automated food production line. An automated sausage food production line consists of several workstations or stages in series integrated into one system by a common transfer mechanism and a common control system. The movement of materials between stations is automated. There are six distinct stages in making sausage: kneading, forming, topping, baking, proofing, and wrapping. The programmable logic controller is used to implement these stages. Given the extensive length of the period covered, it is hoped that this paper will serve as a valid data source for food product manufacturers who wish to improve the output and operation of the production lines they manufacture and run, respectively. It can also be valuable to reliability and manufacturing systems analysts, who wish to model and analyze real manufacturing systems. This paper uses availability and reliability to determine the effectiveness, durability and quality of a production line.

\section{METHODOLOGY}

\subsection{Materials}

The following items are needed in a programmable logic controller (PLC).

(i) Programming device: A personal computer (PC), with STEP 7 Micro/WIN installed is used as a programming device with the S7-200.

(ii) Programming software: A software program S7-200 is required to tell the PLC what instructions it must follow. The S7-200 uses a Windows-based software program called STEP 7-Micro/WIN32.

(iii) Connector cables: A special cable referred to as a (Personal Computer /Point to Point Interface) 
PC/PPI cable, is needed when a personal computer is used as a programming device. DIP switches on the PC/PPI cable are used to select an appropriate speed (baud rate) at which information is passed between the PLC and the computer.

(iv) Programming Language: Ladder Logic Diagram (LAD) is the programming language used with PLCs. The left vertical line of a ladder logic diagram in figure 2 represents the power portion. The output element or instruction represents the neutral or returns path of the circuit. The right vertical line, which represents the return path on a hard-wired control line diagram is omitted. Ladder logic diagrams are read from left-to-right, top-to-bottom. A network is any implemented circuit or system. A network may have several elements, but only one output coil. I0.0, I0.1 represents the inputs and Q0.0 represents the output relay or coil of a ladder logic diagram as shown in Figure 1.

These materials are available in the BIGI food production firm

\subsection{Methods}

Table 1 shows the workstations and machines of the BIGI production line. The parenthesis below the machine or workstation shows the processing time per BIGI.

\subsection{Data Collection}

Three years of data were collected from a BIGI food production Industry. Table 2, 3 and 4 shows the data collected for the first, second-year and third-year period. Table 5 also shows the overall data for the three years combined.

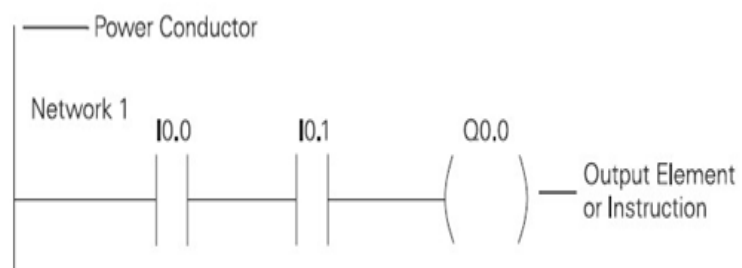

Figure 1: Ladder Logic Diagram

Table 1: The Workstations and machines of a Production line

\begin{tabular}{|l|l|l|l|l|}
\hline Workstations & & \multicolumn{2}{|c|}{ Machines } & \\
\hline WS.1 & M.1.1 & M.1.2 & M.1.3 & \\
\hline Kneading & Flour silo & Mixer & Elevator-tipping device & \\
\hline & $(3 \mathrm{~min})$ & $(25 \mathrm{~min})$ & $(1 \mathrm{~min})$ & \\
\hline WS.2 & M.2.1 & M.2.2 & & \\
\hline Forming & Lamination machine & BIGI machine & & \\
\hline & $(30 \mathrm{~min})$ & $(5 \mathrm{~min})$ & & \\
\hline WS.3 & M.3.1 & & & \\
\hline Topping & Topping machine & & & \\
\hline & $(5$ min) & & & \\
\hline WS.4 & M.4.1 & & & \\
\hline Baking & Baking oven & & & M.5.4 \\
\hline & $(2$ min $)$ & & M.5.3 & Unload zone \\
\hline WS.5 & M.5.1 & M.5.2 & \\
\hline Proofing & Load zone & Transporter & Pan cooling unit & \\
\hline (50 min) & & & & \\
\hline WS.6 & M.6.1 & M.6.2 & M.6.3 & \\
\hline Wrapping & Lifting machine & Wrapping machine & Carton machine & \\
\hline (8 min) & & & & M.7.4 \\
\hline WS.7 & M.7.1 & M.7.2 & M.7.3 & Air supply \\
\hline Exogenous & Electric power & Water supply & Gas supply & \\
\hline
\end{tabular}


Table 2: Data for the first year

\begin{tabular}{lllllll}
\hline Month & A1 & A2 & A3 & A4 & A5 & A6 \\
\hline January & 0 & 1 & 0 & 1 & 1 & 0 \\
February & 1 & 1 & 0 & 0 & 1 & 1 \\
March & 0 & 0 & 1 & 1 & 1 & 1 \\
April & 1 & 1 & 0 & 1 & 1 & 1 \\
May & 0 & 0 & 0 & 1 & 1 & 1 \\
June & 1 & 1 & 1 & 1 & 1 & 0 \\
July & 0 & 1 & 1 & 0 & 1 & 1 \\
August & 1 & 1 & 0 & 1 & 1 & 1 \\
September & 1 & 1 & 1 & 1 & 1 & 1 \\
October & 1 & 0 & 0 & 0 & 0 & 1 \\
November & 1 & 1 & 0 & 0 & 1 & 1 \\
December & 1 & 1 & 1 & 1 & 1 & 1 \\
\hline Total & 8 & 9 & 5 & 8 & 11 & 10 \\
\hline
\end{tabular}

Table 3: Data for the second year

\begin{tabular}{lllllll}
\hline Month & A1 & A2 & A3 & A4 & A5 & A6 \\
\hline January & 1 & 1 & 1 & 1 & 1 & 1 \\
February & 1 & 1 & 1 & 1 & 1 & 0 \\
March & 1 & 1 & 1 & 0 & 1 & 1 \\
April & 1 & 1 & 0 & 1 & 1 & 1 \\
May & 1 & 0 & 0 & 1 & 1 & 1 \\
June & 1 & 1 & 1 & 0 & 0 & 0 \\
July & 1 & 0 & 0 & 0 & 1 & 1 \\
August & 1 & 1 & 1 & 1 & 1 & 1 \\
September & 0 & 0 & 0 & 0 & 0 & 0 \\
October & 0 & 1 & 0 & 1 & 0 & 1 \\
November & 1 & 0 & 1 & 1 & 1 & 1 \\
December & 1 & 0 & 1 & 0 & 1 & 0 \\
\hline Total & 10 & 7 & 7 & 7 & 9 & 8 \\
\hline
\end{tabular}

Table 4: Data for the third year

\begin{tabular}{lllllll}
\hline Month & A1 & A2 & A3 & A4 & A5 & A6 \\
\hline January & 1 & 1 & 0 & 1 & 1 & 0 \\
February & 0 & 1 & 1 & 1 & 1 & 1 \\
March & 0 & 1 & 1 & 1 & 1 & 0 \\
April & 1 & 1 & 1 & 0 & 1 & 1 \\
May & 1 & 1 & 1 & 1 & 1 & 1 \\
June & 0 & 0 & 1 & 1 & 1 & 1 \\
July & 1 & 1 & 1 & 1 & 0 & 0 \\
August & 1 & 0 & 1 & 1 & 0 & 1 \\
September & 1 & 1 & 1 & 1 & 1 & 1 \\
October & 1 & 0 & 0 & 0 & 0 & 1 \\
November & 1 & 1 & 1 & 1 & 1 & 1 \\
December & 1 & 1 & 1 & 1 & 1 & 0 \\
\hline Total & 9 & 9 & 10 & 10 & 9 & 8 \\
\hline
\end{tabular}

Table 5: Data summary for the three years

\begin{tabular}{lllllll}
\hline Year & A1 & A2 & A3 & A4 & A5 & A6 \\
\hline First & 8 & 9 & 5 & 8 & 11 & 10 \\
Second & 11 & 7 & 7 & 6 & 9 & 8 \\
Third & 9 & 9 & 10 & 10 & 9 & 8 \\
\hline Total & 28 & 25 & 22 & 24 & 29 & 26 \\
\hline
\end{tabular}

The mean time to repair (MTTR) is given by equation (1) as

$$
M T T R=\frac{\text { Td for each month }}{\text { number of failure }}
$$

where TD is total downtime, NF is the number of failures. The mean time before/between failures (MTBF) is given by equation (2)

$$
M T B F=\frac{\text { Tui for each month }}{\text { Number of failure }}
$$

where TUI is the uptime before failure. The reliability (RT) is given by equation (3)

$$
R T=\frac{M T B F}{M T B F+M T T R}
$$

The availability A is given by equation (4) as

$$
A=\frac{T U I}{T U I+T D}
$$

The Failure rate $\lambda$ is given by equation (5) as

$$
\lambda=\frac{\text { Number of failures }}{\text { TUI for each month }}
$$

\section{RESULTS AND DISCUSSION}

The results of the three years and the overall mean period on the reliability assessment of PLC is presented in Tables 6, 7, 8 and 9.

Table 6: Results of computed parameters for the first year

\begin{tabular}{llllll}
\multicolumn{6}{c}{$y e a r$} \\
\hline Month & NF & TD & TUI & MTTR & MTBF \\
\hline January & 3.00 & 48.00 & 696.00 & 16.00 & 232.00 \\
February & 4.00 & 17.00 & 655.00 & 4.25 & 163.75 \\
March & 4.00 & 84.00 & 660.00 & 21.00 & 165.00 \\
April & 5.00 & 100.00 & 620.00 & 20.00 & 124.00 \\
May & 3.00 & 9.00 & 735.00 & 3.00 & 245.00 \\
June & 5.00 & 54.00 & 666.00 & 10.80 & 133.20 \\
July & 4.00 & 121.00 & 623.00 & 30.25 & 155.75 \\
August & 5.00 & 200.00 & 544.00 & 40.00 & 108.80 \\
Sept. & 6.00 & 310.00 & 410.00 & 51.70 & 68.30 \\
October & 2.00 & 70.00 & 674.00 & 35.00 & 337.00 \\
Nov. & 4.00 & 160.00 & 560.00 & 40.00 & 140.00 \\
Dec. & 6.00 & 206.00 & 538.00 & 34.30 & 89.66 \\
\hline Total & 51.00 & 1379.00 & 7381.00 & 306.30 & 1962.46 \\
\hline
\end{tabular}


i. Total number of failure alarms for the first year was 51

ii. Total Down Time (TD) for the first year was 1,379

iii. The total up times (TUI ) before failures for the first year was; TUI $=7,381$

iv. The mean time to repair MTTR for the first year was $\quad M T T R=\frac{\text { total } T D}{\text { no of } \text { failure }}=\frac{1,379}{51}=$ 27.039

v. The mean time before/between failures MTBF for the year was also ascertained using $M T B F=\frac{\text { Total } \text { Tui }}{\text { no of failure }}=\frac{7381}{51}=144.725$

vi. The reliability is $\mathrm{RT}=\frac{M T B F}{M T B F+M T T R}=$ $\frac{1962.46}{1962.46+306.3}=\frac{1962.46}{2268.76}=0.8649$

vii. The availability $\mathrm{A}=\frac{T U I}{T U I+T D}=\frac{7381}{7381+1379}=$ $\frac{7381}{8760}=0.843$

Table 7: Results of computed parameters for the second year

\begin{tabular}{llllll}
\hline Month & NF & TD & TUI & MTTR & MTBF \\
\hline January & 6.00 & 70.00 & 674.00 & 11.70 & 115.66 \\
February & 5.00 & 64.00 & 608.00 & 12.80 & 121.60 \\
March & 5.00 & 25.00 & 719.00 & 5.00 & 143.80 \\
April & 5.00 & 100.00 & 620.00 & 20.00 & 124.00 \\
May & 4.00 & 98.00 & 646.00 & 24.50 & 161.50 \\
June & 3.00 & 110.00 & 610.00 & 36.70 & 203.30 \\
July & 3.00 & 80.00 & 664.00 & 26.70 & 221.33 \\
August & 6.00 & 140.00 & 604.00 & 23.30 & 100.66 \\
Sept. & 0.00 & 0.00 & 720.00 & 0.00 & 0.00 \\
October & 3.00 & 96.00 & 648.00 & 23.00 & 216.00 \\
Nov & 5.00 & 164.00 & 556.00 & 32.80 & 111.20 \\
Dec & 3.00 & 190.00 & 554.00 & 63.30 & 176.66 \\
\hline Total & 48.00 & 1137.00 & 7623.00 & 279.80 & 1700.37 \\
\hline & & & & &
\end{tabular}

i. Total number of failure alarms for the second year was 48

ii. Total Down Time (TD) for the second year was 1,137

iii. The total up times (TUI) before failures for the second year was; TUI $=7,623$

iv. The mean time to repair MTTR for the second year was $\quad M T T R=\frac{\text { total } T D}{\text { no of failure }}=\frac{1,137}{48}=$ 23.6875

v. The mean time before/between failures MTBF for the year was also ascertained using $M T B F=\frac{\text { Total } T U I}{\text { no of failure }}=\frac{7,623}{48}=158.8125$ vi. The reliability $\mathrm{RT}=\frac{M T B F}{M T B F+M T T R}=\frac{1700.37}{279.8+1700.37}$ $=\frac{1700.37}{1980.17}=0.8586$

vii. The availability $\mathrm{A}=\frac{T U I}{T U I+T D}=\frac{7623}{7623+1137}=$ $\frac{7623}{8760}=0.87$

Table 8: Results of computed parameters for the third year

\begin{tabular}{llllll}
\hline Month & NF & TD & TUI & MTTR & MTBF \\
\hline January & 4.00 & 52.00 & 692.00 & 13.00 & 173.00 \\
February & 5.00 & 90.00 & 582.00 & 18.00 & 116.40 \\
March & 4.00 & 68.00 & 676.00 & 17.00 & 169.00 \\
April & 5.00 & 140.00 & 580.00 & 28.00 & 116.00 \\
May & 6.00 & 384.00 & 360.00 & 64.00 & 60.00 \\
June & 4.00 & 72.00 & 648.00 & 18.00 & 162.00 \\
July & 4.00 & 96.00 & 648.00 & 24.00 & 162.00 \\
August & 4.00 & 56.00 & 688.00 & 14.00 & 172.00 \\
Sept. & 6.00 & 240.00 & 480.00 & 40.00 & 80.00 \\
October & 2.00 & 30.00 & 714.00 & 15.00 & 357.00 \\
Nov. & 6.00 & 264.00 & 456.00 & 44.00 & 76.00 \\
Dec. & 5.00 & 145.00 & 599.00 & 29.00 & 119.80 \\
\hline Total & 55.00 & 1637.00 & 7123.00 & 324.00 & 1763.20 \\
\hline & & & & &
\end{tabular}

i. Total number of failure alarms for the second year was 55

ii. Total Down Time (TD) for the second year was 1,637

iii. The total up times (TUI ) before failures for the second year was; TUI $=7,123$

iv. The mean time to repair MTTR for the second year was $\quad M T T R=\frac{\text { total } T D}{\text { no of failure }}=\frac{1,637}{55}=29.8$

v. The mean time before/between failures MTBF for the year was also ascertained using $M T B F=\frac{\text { Total } T U I}{\text { no of failure }}=\frac{7,123}{55}=129.509$

vi. Computing the reliability of the PLC RT= $\frac{M T B F}{M T B F+M T T R}=\frac{1763.2}{1763.2+324}=\frac{1763.2}{2087.2}=0.844$

vii. The availability $\mathrm{A}=\frac{T U I}{T U I+T D}=\frac{7123}{7123+1637}=$ $\frac{7123}{8760}=0.813$

Table 9: Overall result of computed parameters for the 3 years

\begin{tabular}{llllll}
\hline Year & NF & TD & TUI & MTTR & MTBF \\
\hline First & 51.00 & 1379.00 & 7381.00 & 306.30 & 1962.46 \\
Second & 48.00 & 1137.00 & 7623.00 & 279.80 & 1700.37 \\
Third & 55.00 & 1637.00 & 7123.00 & 324.00 & 1763.00 \\
Total & 154.00 & 4153.00 & 22127.00 & 910.10 & 5426.03 \\
\hline
\end{tabular}

Overall number of failure alarms was 154

i. The overall Down Time (Td) was 4153 
ii. The overall up times (Tui ) before failures was; Tui $=22127$

iii. The overall mean time to repair MTTR was $M T T R=\frac{\text { total } T \text { d }}{\text { no of failure }}=\frac{4153}{154}=26.967$

iv. The overall mean time before/between failures MTBF was also ascertained using $M T B F=\frac{\text { Total } \text { Tui }}{\text { no of failure }}=\frac{22127}{154}=143.681$

v. The reliability of the $\mathrm{PLC}$ is $\mathrm{RT}=\frac{M T B F}{M T B F+M T T R}$ $=\frac{5426.03}{5426.03+910.1}=\frac{5426.03}{6302.25}=0.8609$

Therefore, the overall reliability is 0.8609

vi. The total availability in three years is given as $\mathrm{A}=\frac{22127}{22127+4153}=\frac{22127}{26280}=0.8419$

\section{DISCUSSIONS}

The reliability of the Programmable Logic Controller was above $80 \%$ for the three years. For the first year, the least downtime was 9 hours for May where it also recorded the highest mean time before failure of 245hours. The lower the downtime, the higher the meantime before failure. The second-year has no downtime for September. The third-year has the greatest downtime of 384hours in May where it also has the least value of mean time before failure of 60 hours.The greater the downtime, the smaller the meantime before failure.

\section{CONCLUSIONS}

The study shows that the mean availability of the production line using the Programmable Logic Controller was $84 \%$ while reliability was $86 \%$. Since the key parameters of relay usage or protection are the meantime to repair and the mean time between failures, the average mean time to repair and mean time between failures using programmable logic controller are 303hours and 1808.67 hours. Electromagnetic relay has a higher mean time to repair as it takes longer time to detect the fault. Faults are detected faster by the PLC, which displays all faults on the computer monitor. The programmable logic controller which is made up of microprocessorbased relay has replaced electromagnetic relay due to reduced maintenance carried out on it; performs selftesting, monitoring and also provide event reporting. The use of PLC should be encouraged in industrial automation as the fault can be detected easily, thereby reducing downtime as compared to the use of electromagnetic relay in the control circuitry.

\section{REFERENCES}

[1] Ahmed, O.T.A. 'Industrial production line automation using PLC systems'. A B.Sc thesis submitted to the department of Electrical Electronic Engineering, University of Khartoum 2009

[2] Alexey, P.A. 'Statistical Methods in Reliability Testing'. An M.Sc thesis submitted to the Department of Statistical and Actuarial Science, Faculty of Science, Simon Fraser University 2012.

[3] Liberopoulos, G. and Tsarouhas, P. (2002). 'Systems analysis speeds up Chipita's food processing line Interfaces. 32(3), pp 62-76, 2002.

[4] Inman, R.R. 'Empirical evaluation of exponential and independence assumptions in queuing models of manufacturing systems Production and Operations Management'8(4), pp 409-432, 1999

[5] Georg, F. 'Formal methods in PLC control demonstrated at a flexible manufacturing line'. A paper presented at the America control conference 2002.

[6] Omer, B.A., Muawia, M.A., Altahir, M.H. 'An industrial packaging line design using $P L C$. International Journal of Advances in Engineering and Management vol 1, nos 5, 2014.

[7] Sadegh, V., Amir, V. 'PLC and its applications'. International Journal of Multidisciplinary Science and Engineering, vol2, nos 8, 2011.

[8] Gurevich, V.'Problems with Evaluation of the Reliability of Relay Protection'. Available at https://www.academia.edu.2010.

[9] Tavares, H., Leite, H., Pinto, A., Vidal, P., Santos, J.' 'Applying Reliability Centered Maintenance to a Digital Protective Relay. Conference paper at the $3^{\text {rd }}$ IEEE PES International Conference and Exhibition of the Innovative Smart Grid Technologies (ISGBT Europe) 2012. DOI:10.1109/ISGBTEurope.2012.6465758.

[10] Edmund, O.S., David, W., Hector, J.A.F., Demetrios, A.T., David, A.C. and David, S.E.' Line Protection: Redundancy, Reliability and Affordability. Conference paper at the 64th Annual Conference of Protective Relay Engineers 2011. 